\section{Stanford looks to the west \\ Palo Alto}

STANFORD University is about to become the first US university directly to tap Japan's strengths in scientific and technological innovation. Following the signing of an agreement with Kyoto University at the end of last year, plans are now being completed for the construction of a centre in Kyoto that will allow US science and engineering students to carry out some of their undergraduate and graduate studies in Japanese industrial companies.

Stanford has benefited enormously from close links between its science and engineering schools and new high-technology industries, in particular the semi-conductor and computer industries of Silicon Valley and the emerging biotechnology industries in the San Francisco region. Both are industries with good reason to fear Japanese competition - or to welcome cooperation. What the future will hold may, according to the proposal for the new centre, depend in part on correcting the 'asymmetry' in the US relation with Japan and producing "Americans who are familiar with Japanese institutions".

The aim is not to produce a new generation of japanologists. That job is to be done in a separate Center for Japanese Studies which Stanford University is setting up in Kyoto with six other US universities. There, students and researchers specializing in Japan studies can find a home. The Stanford Center in Technology and Innovation (SCTI) has a different goal, one that stems from the view that people knowledgeable about Japan are coming from too narrow a base of economic and professional skills. The plan is to take 30 engineering and science students a year, give them 6 months parttime training in "survival Japanese", then send them to Kyoto. With the cooperation of Kyoto University staff they will spend 3 months learning about Japan, with emphasis on the study of technology and innovation and their impact on industrial societies and international trade. Following that will be 3 months of hands-on experience at a Japanese industrial or government institution. The hope is that the contacts and experiences gained will stand the United States in good stead when these people go on to become tomorrow's policy makers, computer engineers and biotechnologists.

Beyond its classroom programme, SCTI will also accommodate researchers and try to build a reputation as a multidisciplinary centre for the study of technology and innovation. Some contribution to the US-Japan trade imbalance may come early on: funds to build the new centre are being raised by donations from Japanese industry.

Alun Anderson

\title{
India carries out large-scale tests of anti-leprosy vaccine
}

\section{New Delhi}

INDIA entered the race to develop an antileprosy vaccine last February when largescale clinical trials of the indigenously developed ICRC vaccine began in the state of Maharashtra. Already, 2,500 healthy household contacts of leprosy patients have been vaccinated, and the figure will reach 40,000 by 1990 .

The vaccine was developed in 1979 by Dr Madhav Deo and his colleagues at the Cancer Research Institute (CRI), in cooperation with the Acworth Leprosy Hospital, G.S. Medical College and the Haffkine Institute, all in Bombay. The project is financed by the Indian Council of Medical Research in New Delhi.

The vaccine contains gamma-ray-inactivated ICRC bacilli, named after the Indian Cancer Research Centre (ICRC), the previous name of CRI. The bacilli are a group of leprosy-derived slow-growing mycobacteria that have been cultivated repeatedly from human lepromata for the past 30 years. Although the exact taxonomical position of the ICRC bacilli is somewhat uncertain, they supposedly belong to the Mycobacterium avium intracellular complex. The fact that the bacilli exhibit antigenic cross-reactivity with M.leprae, especially with reference to Tcell immunity, the dominant host defence against the leprosy germs, forms the scientific basis for the use of ICRC bacilli in the preparation of an anti-leprosy vaccine.

Since 1979, the vaccine has been administered in phase 1 and phase 2 clinical trials to patients with lepromatous leprosy and to healthy subjects in an endemic area. The vaccine enhanced immunity in both patients and healthy subjects. It was cleared for large-scale clinical trial by the Drug Controller of India for both immunotherapy and immunoprophylaxis in October 1984.

A pilot project conducted during the past three years on about 200 healthy household contacts of leprosy patients shows that the vaccine has no untoward side-effects. Fears that lepromin-positive healthy contacts may develop hypersensitivity to leprosy antigens resulting in nerve damage have been set to rest.

The objective of the large-scale trials is to make a comparative evaluation of the immunoprophylactic efficacy of the two vaccines containing either ICRC bacilli or BCG by measuring the incidence of all forms of leprosy in the vaccinated groups. To achieve statistically significant data, 40,000 people will be vaccinated.

Elsewhere in the world, two other large-scale clinical trials have been launched in the past three years using vaccines containing M.leprae from arma- dillo alone or in combination with BCG. The trials in Venezuela are supported by the World Health Organization, while those in Malawi are supported by LEPRA in the United Kingdom.

"Because ICRC anti-leprosy vaccine contains cultivable mycobacteria, it is not only cheap but carries no risk of contamination with animal tissue products", says Deo. The ICRC anti-leprosy vaccine has high acceptability because it is given as a single dose. On the other hand, Deo says, the vaccines containing armadillo-derived M.leprae are costly but and also contain foreign (armadillo) proteins and DNA, and unknown retroviruses that may produce delayed harmful effects.

The Maharashtra trial is the first ever large-scale clinical trial of a vaccine containing cultivable leprosy-derived mycobacteria. The vaccine is important for India, which accounts for one-third of the 12 million cases of leprosy world-wide.

K.S.Jayaraman

\section{BTG's income falls}

\section{London}

InCOME of the British Technology Group (BTG), a state-owned management company set up to assist the commercialization of innovative ideas, fell 23 per cent last year to $£ 14.89$ million, compared with the $1985-86$ figure of $£ 19.35$ million. The net surplus for the year, after tax, was $£ 1.99$ million, compared with $£ 5.77$ million for $1985-86$.

Describing the year as "one of change and consolidation", BTG's annual report claims that its final figures were much as expected, despite two major hiccups during the year: a sharp reduction in income from pyrethrin insecticides because of unforeseen market fluctuations in China, and a slowing down of revenue from royalties on magnetic resonance imaging (MRI) machinery pending legal action against Johnson and Johnson in the United States, which was settled out of court in December. MRI will now become the money spinner for BTG - in June an agreement was signed with General Electric for MRI licensing rights, which included a down-payment thought to be of the order of millions of dollars.

Inventions received from the public sector were up from 355 to 388 , although the number of industrial projects, at 192 , is at its lowest "for several years", which BTG blames on improved availability for financing from other sources and the "relatively low profile which BTG has taken in the industrial finance area over the past few years". Simon Hadlington 